\title{
Addictive Behaviours in Young People- An International Comparative Study of the Construction of an Addictive Personality (France, Switzerland, Quebec)
}

\author{
Mathieu Favennec ${ }^{1}$, Guillaume Bronsard ${ }^{2}$, Morgane Guillou ${ }^{3}$, Jean-Yves Le Reste ${ }^{3}$, \\ Pascale Planche ${ }^{4}$
}

${ }^{1}$ Lab: CREAD (EA3875), Université de Bretagne Occidentale, Brest, France

${ }^{2}$ Département de SHS de l'UFR de médecine et des sciences de la santé, Lab: SPURBO (EA7479), Université de Bretagne Occidentale, Brest, France

${ }^{3}$ UFR de médecine et des sciences de la santé, Lab: SPURBO (EA7479), Université de Bretagne Occidentale, Brest, France ${ }^{4}$ UFR Lettres et Sciences Humaines, Lab: CREAD (EA3875), Université de Bretagne Occidentale, Brest, France

Email: favennectd@gmail.com, guillaume.bronsard@univ-brest.fr, morgane.guillou@univ-brest.fr, lereste@univ-brest.fr, pascale.planche@univ-brest.fr

How to cite this paper: Favennec, M., Bronsard, G., Guillou, M., Le Reste, J.-Y. and Planche, P. (2021). Addictive Behaviours in Young People-An International Comparative Study of the Construction of an Addictive Personality (France, Switzerland, Quebec). Psychology, 12, 1153-1170. https://doi.org/10.4236/psych.2021.127071

Received: July 2, 2021

Accepted: July 26, 2021

Published: July 29, 2021

Copyright $\odot 2021$ by author(s) and Scientific Research Publishing Inc. This work is licensed under the Creative Commons Attribution International License (CC BY 4.0).

http://creativecommons.org/licenses/by/4.0/

\section{(c) (i) Open Access}

\begin{abstract}
Addictive behaviours invite us as clinicians and researchers to focus at all times on the subject hidden behind the addictive object, particularly during the process of subjectivation embodied by adolescence. This article is the fruit of international comparative research to explore the prism of personalities of adolescents and young adults with addictions living in France, Switzerland, and Quebec. This study involved 94 participants, aged between 14 and 32 . They were divided into a clinical group (54 subjects) and a control group (40 subjects). The methodology consisted of two complementary instruments: the MMPI-A personality test and the CaMIR attachment self-report questionnaire. The results highlighted personality traits common to all three countries: depression, psychopathic deviance, anxiety, social discomfort, social alienation, and physical complaints. They also showed the predominance in all addicts of insecure attachment (detached rather than preoccupied). There were also variations between countries. The Swiss and French young people share a particularly low level of hypomania and a high level of social introversion, whereas the Quebec data showed paranoia as a distinctive trait. The results will be discussed from an institutional perspective in particular, taking into account the treatment practices available to young addicts in the three countries in our study.
\end{abstract}




\section{Keywords}

Addictive Behaviours, Youth, Personality, Attachment

\section{Introduction}

Our fate appears to be bound up with that of objects. Humanity is associated with toxic substances and whole societies exist in which drug use is universal. Drugs and alcohol cross borders and travel through time. There is a clear social symptom of substance addiction and it is one of the most visible symptoms of structural malaise in culture (Toubiana, 2011). But what if certain addictive objects, such as alcohol, held the secret to and were the cradle of our civilisation? Written evidence allows us to explore the close link between alcohol and humans in the very distant past. Alcohol appears to play an integral role in the development of language, the arts, and religion.

Research carried out by anthropologists (Hadad, 2020) invites us to consider the earliest origins of addictive behaviour. Across the world, we can find evidence of alcohol consumption, even in the very distant past. The oldest trace dates back 11,600 years to the Neolithic site of Göbekli Tepe, a dry, arid plateau in what is now south-eastern Turkey. Religious ceremonies were performed there, prompting people to settle in order to carry out their rituals on a more regular basis. In certain enclosures devoted to these ceremonies, jar-shaped stone vessels have been found embedded in walls. Analysis reveals the presence of oxalate, a whitish granular chemical deposit produced by mixing water and grains during beer-making. What are the origins of this first link between man and addiction? Does this historical alcohol consumption have much more fundamental roots in the process of subjectivation in human beings? As early as 1885, Ribot highlighted the fact that personality draws a subject towards and into a defined society, while also allowing them to behave in their own distinctively personal manner.

Research in psychology on the consequences of addiction on certain psychological dimensions, such as personality traits, often focuses on alcohol dependence. It would be accompanied in particular by emotional instability, inhibition to action, difficulties in feeling positive emotions and a low level of extraversion (Ruiz, Pincus, \& Dickinson, 2003; Theakston, Stewart, Dawson et al., 2004; Berglund, Fahlke, Berggren, Eriksson, \& Balldin, 2006; Coëffec, Romo, \& Strika, 2009).

In this study, we chose not to target one type of addiction, we assumed the presence of a common base of particularities, particularly in terms of personality traits, in people suffering from substance dependence.

The concept of "personality" within the framework of addiction invites us to refer to the work of Jean Bergeret, and more particularly to what he termed "depressive substance abusers" (Bergeret, 1996). In fact, these subjects appear to exhibit several characteristic personality traits: a depressed mode of organisation 
(mentioned by several theorists including Karila 2006), deep-seated anguish and anxiety, oedipal deprivation, and impulsive behaviour. The link between personality and addiction seems to be a recurring theme among authors attempting to identify personality traits related to addictive behaviours (Cormier \& Reid, 1979; Theakston, Stewart, Dawson et al., 2004; Ruiz, Pincus, \& Schinka, 2008; Kotov, Gamez, Schmidt et al., 2010; Bukhtawer, Muhammad, \& Iqbal, 2014).

Our epistemological position favours traits over structure, but does not attempt to categorise these traits under dogmatic headings. For Huerre and Marty (2007: p. 35), who also refer to personality traits: "certain personality traits can play a role in the establishment of an addictive behaviour, these include: low self-esteem, shyness, self-deprecation, relationship issues, difficulties resolving interpersonal problems, and sensitivity towards the attitudes and behaviours of adults."

Some of these personality traits evoke the model of early maladaptive schemas developed by Young \& Lindemann (1992). These schemas could be established in childhood as part of a reactive and adaptive process to a particular psychosocial environment. Unsatisfied basic affective needs during childhood could lead to the development of early maladaptive schemas. These are unconditional beliefs about the world, oneself and one's relationship to others. These schemas would be responsible for dysfunctions in adulthood and would influence the subject's behaviours and in particular addictive behaviours (Decouvelaere, Graziani, Gackière-Eraldi et al., 2002; Shorey, Anderson, \& Stuart, 2012, Berrewaerts, Pallincourt, Wildemeersch, Desseilles, \& Kempeneers, 2019).

Literature reports that early maladaptive schemas and certain types of attachment could be vulnerability factors associated with addictive behaviours (Camart, Cottea, Leigne, Bouvet, \& Limosin, 2016).

Several studies (Rosenstein \& Horowitz, 1996; Allen, Hauser, \& Borman-Spurrell, 1996; Cooper, Shaver, \& Collins, 1998) have shown, in adolescents, that an insecure attachment style was associated with a greater risk of developing alcohol or substance dependence, compared to secure attachment. Disturbances in the attachment to primary objects associated with other vulnerability factors, in particular psychosocial, would significantly increase the risk of the occurrence of behavioural disorders, but also of internalized disorders, such as depression and anxiety (Fonagy, Target, Gergely et al., 2003; Tereno, Soares, Martins, Sampaio, \& Carlson, 2007; Dykas et al., 2012).

This is why we proposed, in this article, to study the specificities of young adults with addictions in terms of personality traits and attachment styles, by comparing them to subjects without addictions.

Is addiction the result of an encounter between a certain type of subject, a certain personality, and a specific object? Does the addicted subject's personality vary depending on the socio-educational and cultural context in which they were raised? We chose to compare the personality traits and attachment styles of young people living in three French-speaking countries. These are three geographically distinct and culturally diverse countries, but they share a common language as a means of communication. Will these factors-socio-educational 
and cultural background and/or language-have equal weight in the personality traits and attachment styles revealed? Will some be more influential than others? These are the main questions which we will try to address in the research presented here. In order to achieve this objective, we will by definition have to consider society as a whole, and its influences on what is customarily referred to as a "subject".

\section{Method}

\subsection{Participants}

Within the context of this research, we met young people aged between 14 and 32 living in three French-speaking countries-France, Quebec, and Switzerland. These participants were divided into two groups (a clinical group and a control group) according to the following criteria.

All the young people in the clinical group $(n=54)$ were seen in the place in which they were hospitalised or attended consultations. In all three countries, we first searched for institutions that dealt with young people with addictions. We then contacted each institution to present our research and to obtain permission to conduct our data collection there. Once this agreement was obtained, for several days we took part in certain activities of the institution (meals, "therapeutic" coffee) and stayed in the communal living areas in order to initiate the meeting with the young people. This strategy allowed us to meet young people corresponding to our inclusion criteria, to discuss with them, to explain our study individually to those who were interested and to obtain their consent to participate.

Every dual relationship meeting took place in an office in the institution. The inclusion criteria were as follows: being between 14 and 26 years of age, receiving treatment for at least one addiction, being a French-speaker, and giving consent to take part in the research (and their parents if they were minors).

The clinical group from each country comprised:

- 18 French subjects aged between 15 and $32^{1}$ (average age 20 years and 2 months).

- 18 Quebecer subjects aged between 14 and 24 (average age 18 years).

- 18 Swiss subjects aged between 15 and 26 (average age 19 years and 3 months).

All participants in the control group selected $(n=40)$ were volunteers who came forward after a presentation of the research in educational institutions. The inclusion criteria were as follows: being between 14 and 26 years of age, never having received treatment for addictive behaviour, and being a French-speaker. We met with each volunteer individually to explain the research process, and in particular the need to complete two tests. Young people who agreed to participate signed the consent form (or their parents in the case of minors). Data col-

${ }^{1}$ One participant was 32 years old, but we decided to include him in the study because he presented several signs of an ongoing adolescent subjectivation process: rejection of authority, boundary testing, ambivalence towards parental figures (ambivalent desire for dependence and independence), risk-taking behaviours, speech punctuated with neologisms or reappropriations, and body markings. 
lection required two one-and-a-half-hour meetings with each participant, in a dedicated office, for the tests and the reporting of the results.

The control group for each country comprised:

- 13 French subjects aged between 14 and 18 (average age 16 years and 2 months).

- 13 Quebecer subjects aged between 15 and 18 (average age 16 years and 7 months).

- 14 Swiss subjects aged between 16 and 20 (average age 17 years and 7 months).

\subsection{Instruments}

\subsubsection{The Minnesota Multiphasic Personality Inventory-Adolescent} (MMPI-A)

The MMPI-A is a self-report questionnaire for adolescents, developed in the United States (Butcher, Williams et al., 1992). In our study, the $1998^{2}$ revised version published in French was used.

This personality inventory consists of a booklet containing 478 items (numbered true/false statements)-e.g., No.85 "My hardest battles are with myself"-to which the subject must respond as spontaneously as possible. The subject records their response to each statement on a separate dedicated answer sheet. The instructions printed on the booklet are as follows: "Read each statement and decide whether it is true as applied to you or false as applied to you. Write your answers on the answer sheet ... [...]. If a statement is true or mostly true, select $\mathrm{T}$; if a statement is false or mostly false, select $\mathrm{F}$. If a statement does not apply to you, make no mark on the answer sheet. But try to give a response to every statement." This personality test must be administered in a single session, with rest breaks for the subject if required. Certain criteria for sitting the test are necessary to ensure the reliability of the results obtained: the subject must be able to read, have good eyesight with or without corrective lenses, must be sufficiently stable (in terms of motor skills), and must not be suffering from confusion. The test venue must be quiet, without any contextual distractors which could impair concentration. All of these conditions were verified in the context of our data collection. It was initially designed for a 14 - to 18 -year-old sample, but we decided to present it to our subject sample groups as almost all of the young people in our control groups fell into this age range (except for a 20 -year-old Swiss subject), as did the majority of the young people with addictions in our clinical groups. Certain people in these clinical groups were over the age of 18, but their personal and family characteristics (emotional immaturity, living with their parents) demonstrated that they were still rooted in an adolescent process.

Answers to the MMPI-A items can be scored against 10 basic clinical scales: Hypochondriasis, Depression, Hysteria, Psychopathic Deviate, Masculinity/Femininity, Paranoia, Psychasthenia, Schizophrenia, Hypomania, and Social Introversion, and against sub-scales (Anxiety-Family, Anxiety-Body, D1, D2, etc.) which can be ${ }^{2}$ Éditions du Centre de Psychologie Appliquée (ECPA). 
used to clinically refine data collected with the basic data scales.

The graphical representation of the scores obtained on the scales in the form of a histogram produces a personality profile of the subject and specifically highlights dominant personality traits.

The ten basic scales which constitute the MMPI-A can be interpreted according to their respective $\mathrm{T}$ scores. The clinical threshold indicating the presence of a disorder is $\mathrm{T}=65$. With a score of $\mathrm{T} \geq 65$, there is a significant probability that the behavioural descriptors for the scale apply to the subject who took the test. Scores of between 60 and 64 reflect a moderate increase and can be used to diagnose certain deviant behaviours if coupled with other data. $\mathrm{T}$ scores of between 50 and 60 should not be interpreted. No particular interpretative hypothesis in the literature is associated with very low $\mathrm{T}$ scores $(<50)$, however, they should be noted by the clinician and could possibly point to interesting aspects of the subject's personality (Butcher, Williams et al. 1998). The scales are calibrated differently for Male and Female subjects.

\subsubsection{Q-Sort Questionnaire (CaMIR)}

CaMIR was developed by Pierrehumbert, Karmaniola, Sieye, Meister, Miljkovitch, and Halfon (1996). The test requires the subject to sort 72 cards. Each card features a statement about attachment. The test comprises three types of statement printed on the cards:

- statements relating to life in the family of origin, which are generally framed in the past tense, or clearly mention terms such as "child", "parent" or "family of origin".

- statements describing experiences in the family or in a current relationship with a partner, usually referring to "close relatives", which are always framed in the present (the current family can be the family of origin).

- statements relating to the valorisation of certain types of behaviour or family functioning.

The test can be used with people of all ages (from adolescence to old age), of either sex, and with diverse experiences (parent or non-parent, currently living in their family of origin, living alone or with a partner, having grown up in a two-parent, single-parent or foster family).

CaMIR provides thirteen evaluation scales: parental intrusion, preoccupation with family, resentment at infantilisation, parental support, family support, gratitude for support, parental unavailability, family distance, resentment of rejection, parent-related trauma, blocked memories, parental abdication, and regard for hierarchy.

These thirteen scales are associated with the three classic types of attachment described in children (Ainsworth, 1989) and studied by CaMIR. They continue to operate in adulthood and to shape relationships with other people and the potential for autonomy (Main, 1995):

- Secure Attachment: the child trusts their attachment figure and their availability. They exhibit positive behaviour towards their mother and are at ease 
and cooperative with her. They also obey her willingly. The maternal figure offers a secure base from which they will venture out and explore. A secure initial attachment fosters successful autonomy.

- Insecure Attachment-Detached: the child shows little reaction to separation and avoids proximity-seeking or interaction with their mother. These children are anxious and avoidant, and attachment does not provide the expected comfort in anxiety-inducing situations. This absence creates frustration which is likely to manifest itself in anger. These children will become invested "elsewhere" in order to fill the gap left by their parent figures. They tend to seek autonomy at an early age.

- Insecure Attachment-Preoccupied: this child cries more than usual. They react to separation by showing immediate distress. They display resistance to contact and interactions with the parent, and ambivalence. These children exhibit disinvestment or overinvestment in interpersonal behaviour. They adopt behaviours which have similarities with traumatic games.

The CaMIR test presents the subject with a progressive process for arranging cards (in three piles, then five piles, followed by an evening-up stage depending on the number of cards in each pile). This arrangement can be scored on the basis of the categories of card selected and against each of the thirteen scales. Scores vary between 0 and 100. A mean score of 50 is the clinical threshold at which the scale becomes significant in the subject profile. Once scoring is complete, it is possible to capture data in the spreadsheet supplied with the test to obtain a graphic representation of the scales as a whole in a histogram, and notably of the type of dominant attachment exhibited by the subject.

The tests were individually administered to the participants in a quiet room. All testing with both groups was conducted by the same psychologist (M. F).

An informed consent form was signed for each study participant (either by themselves or by their parents if they were minors).

All study procedures were approved by the local ethics committee of the University of Brest ( $\left.n^{\circ} 03 / 2017-03\right)$.

\section{Results}

Results obtained from the MMPI-A were initially analysed by country, comparing the results of the clinical group and the control group. In the next phase, a cross-country comparative study was carried out to extract potential similarities and/or differences between the characteristic personality traits of young adults with addictions.

In order to answer our initial question, analysis of the results obtained using CaMIR focused from the outset on the types of dominant attachment which emerged in each country (by comparing the clinical group and the control group).

Data analysis was performed using JASP statistical software (version: 0.11.1/ October 7, 371 2019). Our analysis of the results consisted of comparing the performances of the previously defined groups in each of the tests for which data 
was collected (Independent Samples T-Test, ANOVA) in order to identify statistically significant differences between them (with a threshold of $p \leq .05$ ).

\subsection{Results from Each Country on the MMPI-A Basic Scales}

As mentioned above, the clinical threshold for each scale indicating entry to a zone of potential psychological issues is 65, and furthermore, the zone below 50 is considered significant. To avoid cluttering the tables, we have therefore chosen to present the results on the basic clinical scales where the mean score on a scale is $\geq 65$ or $<50$.

In the French groups, as shown in Table 1, the clinical group obtained a significantly higher mean score on the depression scale $(\mathrm{t}=-6.733, p<.001)$ and psychopathic deviate scale $(\mathrm{t}=-5.305, p<.001)$ than the control group. There was no significant difference between the two groups on the social introversion scale $(p>.05)$, but the mean score was only above 65 in the clinical group.

There was no significant difference between the groups on the hypomania scale. The mean scores on this scale were particularly low $(<50)$.

In addition, in the control group, no mean score on the basic clinical scales reached the clinical threshold of 65 .

In the Swiss groups, as shown in Table 2, the clinical group obtained a significantly higher mean score on the depression scale $(\mathrm{t}=-7.396, p<.001)$, psychopathic deviate scale $(\mathrm{t}=-4.648, p<.001)$ and social introversion scale $(\mathrm{t}=$ $-3.411, p=.002)$ than the control group.

There was no significant difference between the groups on the hypomania scale. The mean scores on this scale were particularly low $(<50)$, as was the case for the French young people.

In addition, in the control group, no mean score on the basic clinical scales reached the clinical threshold of 65 .

Table 1. Mean scores (and Standard Deviation) for French young people on the MMPI-A.

\begin{tabular}{cccc}
\hline Clinical scale & Clinical group & Control group & $p$ value (t-test) \\
\hline Depression (D) & & & \\
Mean score & 82 & 58.92 & $p<.001$ \\
SD & 11.3 & 5.4 & \\
Psychopathic deviate (Pd) & & & $p<.001$ \\
Mean score & 75.55 & 61.92 & \\
SD & 8.3 & 4.5 & \\
Social introversion (Si) & & & \\
Mean score & 65.44 & 58.31 & \\
SD & 13.6 & 5.4 & \\
Hypomania (Ma) & & & $p>.05$ \\
Mean score & 43.89 & 46.51 & \\
SD & 7.8 & 7.4 &
\end{tabular}

* The mean scores $\geq 65$ or $<50$ appear in bold type. 
Table 2. Mean scores (and Standard Deviation) for Swiss young people on the MMPI-A.

\begin{tabular}{cccc}
\hline Clinical scale & Clinical group & Control group & $p$ value (t-test)* \\
\hline Depression (D) & & & \\
Mean score & 80.78 & 57.36 & $p<.001$ \\
SD & 11.42 & 6.23 & \\
Psychopathic deviate (Pd) & & & $p<.001$ \\
Mean score & 74.4 & 62.35 & \\
SD & 7.88 & 6.45 & $p=.002$ \\
Social introversion (Si) & & 56.78 & \\
Mean score & 67.78 & 5.38 & \\
SD & 12.23 & & \\
Hypomania (Ma) & & 47.21 & \\
Mean score & 43.33 & 5.4 & \\
SD & 6.99 & & \\
\hline
\end{tabular}

* The mean scores $\geq 65$ or $<50$ appear in bold type.

In the Quebec groups, as shown in Table 3, the clinical group obtained a significantly higher mean score on the depression scale $(\mathrm{t}=-2.766, p=.001)$ and psychopathic deviate scale $(\mathrm{t}=-2.142, p=.041)$ than the control group.

There was no significant difference between the groups on the paranoia scale, but the mean score was only above 65 in the clinical group.

We note the distinctive personality profile of the Quebec clinical group compared to the young French and Swiss addict groups: the mean score on the paranoia scale was not significantly different from the psychopathic deviate scale $(\mathrm{t}=.992, p=.335)$ or the depression scale $(\mathrm{t}=.391, p=.701)$.

In addition, in the control group, no mean score on the basic clinical scales reached the clinical threshold of 65 .

Table 3. Mean scores (and Standard Deviation) for Quebecer young people on the MMPI-A.

\begin{tabular}{cccc}
\hline Clinical scale & Clinical group & Control group & $p$ value (t-test) \\
\hline Depression (D) & 67.17 & 58.69 & \\
Mean score & 11.34 & 5.39 & $p=.001$ \\
SD & & & \\
Psychopathic deviate (Pd) & 68 & 61.46 & $p=.041$ \\
Mean score & 9.4 & 6.67 & \\
SD & & & \\
Paranoia (Pd) & 65.94 & 60.23 & $p>05$ \\
Mean score & 9.00 & 5.63 & \\
SD & & & \\
\hline
\end{tabular}

*The mean scores $\geq 65$ or $<50$ appear in bold type.

\subsection{Cross-Country Comparative Study of the Results Obtained on the Basic MMPI-A Scales}

We now propose to conduct a cross-country comparative study in order to highlight possible commonalities and/or discrepancies between the personality traits 
characterizing young people with addictions.

As shown in Table 4, two clinical scales, depression and psychopathic deviate, had mean scores of $>65$ in all three countries: they constitute the "intercontinental" personality of young addicts.

Differences in personality profile appeared between these three countries. The mean scores obtained by the French and Swiss clinical groups on the depression (D), psychopathic deviate (Pd) and social introversion ( $\mathrm{Si}$ ) scales were not statistically different (respectively: $\mathrm{t}=.322, p=.749 ; \mathrm{t}=.410, p=.685$ and $\mathrm{t}=-.541, p$ $=.592$ ), but comparison of the three means was highly significant (respectively: $\mathrm{F}(2.51)=9.433, p<.001 ; \mathrm{F}(2.51)=4.069, p=.023$ and $\mathrm{F}(2.51)=3.706, p$ $=.031)$. This result showed the lesser weight of these personality traits in the profile of young Quebecers.

Table 4. Mean scores (and Standard Deviation) on the basic clinical scales where the score is $\geq 65$ or $<50$ in the three countries on the MMPI-A.

\begin{tabular}{|c|c|c|c|c|c|}
\hline \multirow[b]{2}{*}{ Clinical groups } & \multicolumn{5}{|c|}{ Basic Clinical Scales* } \\
\hline & Depression & $\begin{array}{c}\text { Psychopathic } \\
\text { deviate }\end{array}$ & $\begin{array}{c}\text { Social } \\
\text { introversion }\end{array}$ & Hypomania & Paranoia \\
\hline \multicolumn{6}{|l|}{ France } \\
\hline Mean score & 82.00 & 75.55 & 65.44 & 43.88 & 59.77 \\
\hline $\mathrm{SD}$ & 11.35 & 8.38 & 13.62 & 7.79 & 6.01 \\
\hline \multicolumn{6}{|l|}{ Switzerland } \\
\hline Mean score & 80.77 & 74.44 & 67.77 & 43.33 & 59.27 \\
\hline $\mathrm{SD}$ & 11.42 & 7.88 & 12.23 & 6.99 & 5.89 \\
\hline \multicolumn{6}{|l|}{ Quebec } \\
\hline Mean score & 67.167 & 68.00 & 56.88 & 59.22 & 65.94 \\
\hline SD & 11.34 & 9.40 & 11.98 & 12.61 & 9.00 \\
\hline$p$ value ( F) & $p<.001$ & $p=.023$ & $p=.031$ & $p<.001$ & $p=.011$ \\
\hline
\end{tabular}

* The mean scores $\geq 65$ or $<50$ appear in bold type.

The mean scores obtained by the French and Swiss clinical groups on the hypomania scale were particularly low and were not statistically different $(t=.225$, $p=.823)$, but comparison of the three means was significant $(\mathrm{F}(2.51)=16.345$, $p<.001)$. The mean scores for the clinical and control groups were $59.22(12.6)$ and 53.07 (8.08) for the young Quebecers respectively. They were not significantly different and they were in the non-significant zone of particularities for the MMPI-A. This result showed the lesser importance of this personality trait in young Quebecer addicts.

On the paranoia scale $(\mathrm{Pa})$, the mean score was only above 65 in the Quebec clinical group. The mean scores in the French and the Swiss clinical groups were in the normal range for the scale. The comparison of the three means was significant $(\mathrm{F}(2.51)=4.899, p=.011)$, thus confirming that this personality trait appeared to be significant only in the profile of young Quebecers. Furthermore, the MMPI-A provides the option of scoring against subscales. Some of these appeared to be significant in our results, supplementing the data from the basic clinical scales. 
As shown in Table 5, 4 subscales showed a mean score of $>65$ in the three countries: A-anx (Adolescent-anxiety), subjective depression (D1), mental dullness (D4), and self-alienation (Pd5). The comparison of the three means was not significant except in the case of the subjective depression scale. This personality trait was more prevalent in the French and Swiss clinical groups than in the Quebec clinical group $(\mathrm{F}(2.51)=10.342, p<.001)$. It refers to a diffuse feeling of depression. This result corroborated the findings already highlighted by the basic clinical depression scale.

The A-anx scale reflects an intense feeling of anxiety leading to marked symptoms of nervousness and/or worry. The second subscale relating to depression-mental dullness (D4) - refers to the difficulty in thinking and mental confusion that often accompany a depressive state. The self-alienation scale $(\operatorname{Pd} 5)$ highlights ego issues and an intrinsic fragility in particular. These personality traits were equally weighted in the three clinical groups.

In addition, in the control group, no mean score on the clinical subscales reached the clinical threshold of 65 .

Table 5. Significant clinical subscales for the three countries (total mean score and standard deviation).

\begin{tabular}{|c|c|c|c|c|}
\hline \multirow[b]{2}{*}{ Clinical groups } & \multicolumn{4}{|c|}{ Clinical subscales } \\
\hline & $\begin{array}{c}\text { A-anx } \\
\text { (Adolescent -anxiety) }\end{array}$ & $\begin{array}{c}\text { Subjective } \\
\text { depression (D1) }\end{array}$ & $\begin{array}{c}\text { Mental } \\
\text { dullness (D4) }\end{array}$ & $\begin{array}{c}\text { Self-alienation } \\
\text { (Pd5) }\end{array}$ \\
\hline \multicolumn{5}{|l|}{ France } \\
\hline Mean score & 68.33 & 84.05 & 71.83 & 68.00 \\
\hline SD & 5.93 & 10.63 & 11.29 & 8.11 \\
\hline \multicolumn{5}{|l|}{ Switzerland } \\
\hline Mean score & 67.61 & 80.44 & 72.38 & 66.94 \\
\hline $\mathrm{SD}$ & 5.67 & 9.53 & 10.07 & 7.00 \\
\hline \multicolumn{5}{|l|}{ Quebec } \\
\hline Mean score & 66.83 & 68.00 & 68.61 & 66.44 \\
\hline $\mathrm{SD}$ & 10.33 & 12.90 & 13.44 & 11.08 \\
\hline$p$ value $(\mathrm{F})$ & $p=.0854$ & $p<.001$ & $p=.581$ & $p=.867$ \\
\hline
\end{tabular}

\subsection{Cross-Country Comparative Study of Results Obtained on CaMIR}

In order to ascertain whether personality traits previously identified in young addicts were associated with a relatively secure type of attachment to primary objects, we will focus on the analysis of the CaMIR results for different types of attachment in the three countries. It should be borne in mind that the clinical threshold for the predominance of a type of attachment is $>50$.

As shown in Table 6, the control group in each country was characterised by secure attachment, with no significant differences between them $(p>.05)$. Concurrently, this type of attachment was infrequent in the clinical groups of each country, with no significant difference between them $(\mathrm{F}(2.51)=1.462, p=.241)$. 
Table 6. Mean scores and standard deviation for each type of attachment in each country (comparison of the clinical group and the control group).

\begin{tabular}{|c|c|c|c|c|}
\hline \multirow{2}{*}{ Country } & \multirow{2}{*}{ Type of attachment } & \multicolumn{3}{|c|}{ Groups } \\
\hline & & Clinical & Control & $p$ value (t-test) ${ }^{*}$ \\
\hline & Secure & & & \\
\hline \multirow[t]{9}{*}{ France } & Mean score & 27.53 & 60.06 & $p<.001$ \\
\hline & SD & 8.3 & 7.41 & \\
\hline & Detached & & & \\
\hline & Mean score & 70.89 & 46.96 & $p<.001$ \\
\hline & SD & 9.3 & 5.30 & \\
\hline & Preoccupied & & & \\
\hline & Mean score & 50.64 & 33.54 & $p<.001$ \\
\hline & SD & 6.64 & 3.78 & \\
\hline & Secure & & & \\
\hline \multirow[t]{9}{*}{ Switzerland } & Mean score & 31.02 & 61.30 & $p<.001$ \\
\hline & SD & 7.67 & 7.31 & \\
\hline & Detached & & & \\
\hline & Mean score & 72.87 & 46.46 & $p<.001$ \\
\hline & SD & 8.5 & 6.00 & \\
\hline & Preoccupied & & & \\
\hline & Mean score & 52.04 & 33.19 & $p<.001$ \\
\hline & SD & 6.10 & 4.29 & \\
\hline & Secure & & & \\
\hline \multirow[t]{8}{*}{ Quebec } & Mean score & 31.60 & 62.06 & $p<.001$ \\
\hline & SD & 7.02 & 11.68 & \\
\hline & Detached & & & \\
\hline & Mean score & 67.57 & 42.74 & $p<.001$ \\
\hline & SD & 7.92 & 6.21 & \\
\hline & Preoccupied & & & \\
\hline & Mean score & 48.26 & 30.53 & $p<.001$ \\
\hline & SD & 5.66 & 4.44 & \\
\hline
\end{tabular}

${ }^{*}$ Mean scores $>50$ appear in bold type.

A detached type of attachment was most common in all three clinical groups, with no significant difference between them $(\mathrm{F}(2.51)=1.739, p=.186)$.

Preoccupied attachment was less frequent than detached attachment in the clinical groups in the three countries. It exceeded the threshold of 50 only in Swiss and French young people, and the comparison of mean scores in the three countries was not statistically significant $(\mathrm{F}(2.51)=1.739, p=.186)$.

Both detached and preoccupied attachment show an insecure attachment to first objects.

\section{Discussion}

Our main objective was to attempt to identify common personality traits in young addicts which differed from those of young people of the same age who had never been treated for addiction. Our aim was also to compare populations 
in three geographically distinct French-speaking countries (France, Switzerland, and Quebec) characterised by different socio-cultural and educational systems in order to identify potential relationships between these contextual variables, personality traits, and the most frequent types of attachment observed among these young people.

Analysis based on data collected using the MMPI-A (basic clinical scales and subscales) revealed first of all the burden of a depressive and anxious personality on young people in the grip of addictive behaviour in all three countries in our study. These personality traits have their origins in life events that have destructured or hampered the construction of self-constancy and adequately high self-esteem (clinical interviews conducted with these young people, which we have chosen not to present here, confirmed these aspects). Depression appears to be the dominant feature in the addictive personality landscape, and it is also independent of the sociocultural context.

These results confirm the findings of certain authors who have demonstrated the link between addiction and depression, including psychiatrist and addiction specialist Laurent Karila: "One of the most frequent mental health issues associated with substance use is depression [...] 80\% of alcohol-dependent subjects will present symptoms of depression in their life [...]. Depressed patients used legal or illegal psychoactive substances to self-medicate." (Karila, 2006: p. 23).

Another personality trait which emerges as having significant weight among the young people in the clinical trials in our three countries is psychopathic deviance. This personality trait can be pronounced in circumstances where "the other" is missing and has not played a part in creating sufficiently firm foundations to forge a social connection nuanced by reciprocal investment. This deviance can have an impact: the dependent youngster no longer believes in their family and social relationships. This can lead them to lie, steal, manipulate, evade, deceive or even assault the other (and hence themselves) in any of the countries involved in our research. Subscale Pd 4, referenced to the psychopathic deviate scale (Pd), showed a significant increase in the clinical groups in the three countries studied, and paints a picture of young people alienated from the other. Psychopathic deviance should not be understood in its popularly perceived sense, but as a psychological personality trait associated not with behavioural problems and a feeling of omnipotence, but with problematic behaviours which serve a purpose: to remove the other in favour of the Self. These young people have experienced a family history characterised by absence and deprivation, which was abusive and even violent. Our results from the CaMIR questionnaire actually demonstrate the predominance of insecure attachment to primary objects. These "deviant" behaviours have a function, which subjects can attempt to describe (for example, psychopathic deviant behaviour in which self-sabotaging of bonds is intended as an escape from a lack of social constancy). This is reflected in this excerpt from an interview with a young person from a clinical group: "I pissed everybody off, I turned my entire family against 
me with my lying, but at least people have stopped bothering me, I don't owe anyone anything anymore". The social introversion scale (Si), which has high mean scores in the French and Swiss clinical groups, confirms the issue of bonds, for these two countries at least. In fact, the high score for this personality trait shows that the Self is not adequately equipped to move towards otherness. This scale combines all the different forms of relationship with the other: social relationships, shyness, embarrassment, social avoidance, low self-esteem, etc.

Based on our thinking, we assume that these psychopathic traits existed long before the emergence of addictive behaviour, as subjects often refer when speaking to a timeframe pre-dating addictions. Thus, psychopathic deviance, like depression, is a structural component of addictive behaviour, irrespective of the educational and sociocultural specificities of the environment in which the young person grew up. This raises the question of the primary cause of addiction issues: certain pathological personality traits or addictions-which came first?

Another personality trait which has a conspicuously high mean score, although only in the clinical group of young Quebecers, is the paranoia scale. This scale, which is above the clinical threshold, brings together symptoms of interpretative ideas, mistrust, feelings of persecution, rigidity, hyper-morality, and hyper-sensitivity. We observed the distinctive personality profile which seems to characterise the Quebec clinical group on three scales, whose scores stand out from the others but not from each other: the psychopathic deviate scale, the depression scale, and the paranoia scale. We can attempt to interpret these results from an institutional perspective. Unlike in France and Switzerland, treatment practices in Quebec are based on psychoeducation. The young person is invited to rediscover and work on their personal values in order to turn away from their pathogenic environment more effectively. This approach helps them to view their living environment as problematic and to focus on themselves, by seeking strategies to achieve freedom and autonomy. "Your institution provides us with a family." said one young person. We can clearly see the compensatory and systemic aspects of an institution which takes over from the family. The institution represents the "Skin-Ego" which is containing, reassuring and re-motivating. It offers the subject effective support and direction. We can hypothesise that high scores on the paranoia scale relate to the expression of resistances, to distrust as a defence mechanism against the other who believes that they understand them, and manages them accordingly. This personality trait may not, therefore, be directly linked to addictive behaviour, but could stem from the specific taking care of these young addicts in Quebec. This particular form of treatment of young addicts could have a greater (or faster?) positive therapeutic effect on depression and psychopathic deviance than treatments which exist in France and Switzerland, thus helping to reduce their symptoms and ultimately achieve a flat profile on the three scales. We should not overlook the fact that we met these young people when they were already being treated for their addictive behaviours and these treatments could already have influenced their way of being and acting. 
Furthermore, we observed abnormally low scores on the hypomania scale for Swiss and French young people in our clinical groups. A hypomanic person needs to be constantly active, and we observed on the contrary, a form of "hypo-activity" in our subjects with addictive behaviours in the interviews which we conducted. The "push to use" associated with addiction has impaired the mechanism for acting, planning ahead, and organising oneself. The domination of the substance and its effects could prompt the subject to annihilate all other desires in order to ritualise his life around the endless circle of addiction. But why does this symptomatology traditionally associated with addiction seem to be less prevalent in the young Quebecers we met? As before, we can hypothesise that this observation has its origins in the differences in treatments between countries. Many Swiss and French subjects told us about the cycle of hospital admissions which earned them the label "chronic sufferers", caught in the revolving door of an institution. We could see here the transferential functions of reactivations of oedipal issues, between the search for security and the desire for emancipation. Moreover, social introversion, which was also more pronounced in French and Swiss youths, may have its basis in this interpretation. When the subject becomes subdued and regresses, they can withdraw in order to refocus, for reassurance, or to protect themselves. French and Swiss institutions could play a third-party mediating role, mothering the subject in order to try to reactivate their subjectivation process.

In addition, our objective was also to identify the dominant type of attachment in each of our groups. We assumed the possibility of glimpsing a deficiency in the family background of these young addicts likely to constitute a basis for the appearance of specific personality traits fostering addictive behaviours. Analysis of scores reveals that detached insecure attachment predominates in the clinical groups from all three countries. This type of attachment indicates that the subject is aware of their attachment issue and is trying to extract themselves from the failing family environment by a process of emancipation/individualisation, irrespective of the socio-cultural environment in which they grew up.

The young people we met in a clinical context described a family environment marked by deprivation, which did not provide adequate primary socialisation. The family environment was the vector for inoperant transmission of stability with, in addition, a legacy of transgenerational addictive behaviour. Although communication, attention, and affection were in short supply, there was no shortage of addictive objects which proliferated everywhere in the family environment. These family connections illustrated a failing internal model from which the subject could not derive any benefits that they could use to develop a sufficiently well-equipped self to face up to otherness and failures. The insecure attachment which we identified in our research among young people exhibiting addictive behaviours is the product of an unstable, deficient or even absent family. Our data confirmed those of other studies that showed a possible link between attachment types, personality traits and addictive behaviours (Allen, 
Hauser, \& Borman-Spurrell, 1996; Molnar, Sadava, De Courville et al., 2010; Miljkovitch et al., 2018).

We compared the personality traits of young people living in three Frenchspeaking countries. Although these are three geographically distinct countries with different educational and socio-cultural practices, we were only able to link the differences observed at the level of the manifestation of certain personality traits to the specificities of taking care in Europe and Quebec. Deficient educational environments in all three countries have created an analogous type of attachment in young people exhibiting addictive behaviours. The most marked personality traits (depression and psychopathic deviance) can be observed among young addicts in all three countries. Beyond these common traits which seem to characterise the personality profiles of young addicts whatever their country of origin, to give us the possibility to highlight a possible differentiation of the personality profile according to the life contexts in the countries which hosted our research, perhaps it would have been necessary for us to have the possibility to meet young addicts before any institutional care.

A longitudinal study beginning in childhood could perhaps confirm a continuity between an insecure attachment observable in childhood, a similar insecure attachment in adolescence, and the establishment of specific psychopathological traits that would provide the basis for the appearance of addictive behaviours. This type of study would bring interesting epistemological depth to the personality profile of young addicts, and to the origins of the specific features highlighted, which could form the basis for appropriately targeted treatments.

Indeed, these findings could have implications for clinical intervention. The young people we met grew up in a deficient family environment resulting in the predominance of an insecure attachment to primary objects and probably to early maladaptive schemas. They grew up in vulnerable families often characterised by a transgenerational recurrence of addictive behaviours. Families that have sometimes been identified and supported for a long time by the social services and in which it would be possible to offer an early intervention programme at home more systematically than is currently the case in France and Switzerland in particular, in order to prevent the deleterious effects of these high psychosocial risk contexts on children. By intervening very early and in a very appropriate way in these families, it might be possible to avoid the meeting between the adolescent and the toxic.

\section{Acknowledgements}

The authors would like to thank T. Sculo, M. Therriault and M. Cattin for their help to include young French people with addictive behaviours.

\section{Conflicts of Interest}

The authors declare no conflicts of interest regarding the publication of this paper. 


\section{References}

Ainsworth, M. S. (1989). Attachments beyond Infancy. American Psychologist, 44, 709-716. https://doi.org/10.1037/0003-066X.44.4.709

Allen, J. P., Hauser, S. T., \& Borman-Spurrell, E. (1996). Attachment Theory as a Framework for Understanding Sequelae of Severe Adolescent Psychopathology: An 11-Year Follow-Up Study. Journal of Consulting and Clinical Psychology, 64, 254-263. https://doi.org/10.1037/0022-006X.64.2.254

Bergeret, J. (1996). Toxicomanie et personnalité. Presses Universitaires de France.

Berglund, K., Fahlke, C., Berggren, U., Eriksson, M., \& Balldin, J. (2006). Personality Profile in Type I Alcoholism: Long Duration of Alcohol Intake and Low Serotonergic Activity Are Predictive Factors of Anxiety Proneness. Journal of Neural Transmission, 113, 1287-1298. https://doi.org/10.1007/s00702-005-0412-3

Berrewaerts, J., Pallincourt, R., Wildemeersch, G., Desseilleset, M., \& Kempeneers, P. (2019). Schémas précoces inadaptés, tempérament et caractère chez des patients présentant une dépendance aux substances psychoactives. Bulletin de psychologie, 562, 243-257. https://doi.org/10.3917/bupsy.562.0243

Bukhtawer, N., Muhammad, S., \& Iqbal, A. (2014). Personality Traits and Self-Regulation: A Comparative Study among Current, Relapse and Remitted Drug Abuse Patients. Health, 6, 1368-1375. https://doi.org/10.4236/health.2014.612168

Butcher, J. N., Williams, C. L., Graham, J. R., Tellegen, A., Ben-Porath, Y. S., Archer, R. P. et al. (1992). Manual for Administration, Scoring, and Interpretation of the Minnesota Multiphasic Personality Inventory for Adolescents: MMPI-A. University of Minnesota Press. https://doi.org/10.1037/t15122-000

Camart, N., Cotte, M., Leignel, S., Bouvet, C., \& Limosin, F. (2016). Dimensions de personnalité, style d'attachement et schémas précoces d'inadaptation chez des patients alcoolo-dépendants: Quelles sont les spécificités liées au sexe? L'Encephale, 42, 523-528. https://doi.org/10.1016/j.encep.2016.05.001

Coëffec, A., Romo, L., \& Strika, L. (2009). Personnalité et impulsivité: Etude portant sur 20 patients alcoolo-dépendants. Alcoologie et addictologie, 31, 327-332.

Cooper, M. L., Shaver, P. R., \& Collins, N. L. (1998). Attachment Styles, Emotion Regulation, and Adjustment in Adolescence. Journal of Consulting and Clinical Psychology, 74, 1380-1397. https://doi.org/10.1037/0022-3514.74.5.1380

Cormier, D., \& Reid, N. (1979). La dépendance de la personnalité dans la Pharmaco dépendance [Personality Dependence in Drug Dependence]. Drug and Alcohol Dependence, 4, 475-487. https://doi.org/10.1016/0376-8716(79)90026-7

Decouvelaere, F., Graziani, P., Gackière-Eraldi, D., Rusinek, S., \& Hautekeete, M. (2002). Hypothèse de l'existence et de l'évolution de schémas cognitifs mal adaptés chez l'alcoolo-Dependant. Journal de thérapie comportementale et cognitive, 12, 43-48.

Dykas, M. J., Woodhouse, S. S., Ehrlich, K. B., \& Cassidy, J. (2012). Attachment-Related Differences in Perceptions of an Initial Peer Interaction Emerge over Time: Evidence of Reconstructive Memory Processes in Adolescents. Developmental Psychology, 48, 13811389. https://doi.org/10.1037/a0027462

Fonagy, P., Target, M., Gergely, G., Allen, G. J., \& Bateman, A. W., \& FRC Psych. (2003). The Developmental Roots of Borderline Personality Disorder in Early Attachment Relationships: A Theory and Some Evidence. Psychoanalytic Inquiry, 23, 412-459. https://doi.org/10.1080/07351692309349042

Hadad, R. (2020). Inactualités de la révolution néolithique: Rousseau, l'Anthropocène et les nouveaux riches de la préhistoire. L' Homme, 2, 291-318. 
https://doi.org/10.4000/lhomme.37622

Huerre, P., \& Marty, F. (2007). Alcool et adolescence. Albin Michel.

Karila, L. (2006). Dépression et addictions. Editions Médicales (Phase 5).

Kotov, R., Gamez, W., Schmidt, F. et al. (2010). Linking “Big” Personality Traits to Anxiety, Depressive, and Substance Use Disorders: A Meta-Analysis. Psychological Bulletin, 136, 768-821. https://doi.org/10.1037/a0020327

Main, M. (1995). Recent Studies in Attachment: Overview, with Selected Implications for Clinical Work. In S. Goldberg, R. Muir, \& J. Kerr (Eds.), Attachment Theory: Social, Developmental, and Clinical Perspectives (pp. 407-474). Analytic Press, Inc.

Miljkovitch, R., Deborde, A.-S., Bernier, A., Corcos, M., Speranza, M., \& Pham-Scottez, A. (2018). Borderline Personality Disorder in Adolescence as a Generalization of Disorganized Attachment. Frontiers in Psychology, 9, 1962. https://doi.org/10.3389/fpsyg.2018.01962

Molnar, D. S., Sadava, S. W., DeCourville, N. H., \& Perrier, C. P. K. (2010). Attachment, Motivations, and Alcohol: Testing a Dual-Path Model of High-Risk Drinking and Adverse Consequences in Transitional Clinical and Student Samples. Canadian Journal of Behavioural Science, 42, 1-13. https://doi.org/10.1037/a0016759

Pierrehumbert, B., Karmaniola, A., Sieye, A., Meister, C., Miljkovitch, R., \& Halfon, O. (1996). Les modèles de relations: Développement d'un auto-questionnaire d'attachement pour adultes. Psychiatrie de l'enfant, 1, 161-206.

Rosenstein, D. S., \& Horowitz, H. A. (1996). Adolescent Attachment and Psychopathology. Journal of Consulting and Clinical Psychology, 64, 244-253. https://doi.org/10.1037/0022-006X.64.2.244

Ruiz, M. A., Pincus, A. L., \& Dickinson, K. A. (2003). NEO PI-R Predictors of Alcohol Use and Alcohol-Related Problems. Journal of Personality Assessment, 81, 226-236. https://doi.org/10.1207/S15327752JPA8103_05

Ruiz, M. A., Pincus, A. L., \& Schinka, J. A. (2008). Externalizing Pathology and the Five-Factor Model: A Meta-Analysis of Personality Traits Associated with Antisocial Personality Disorder, Substance Use Disorder, and Their Co-Occurrence. Journal of Personality Disorders, 22, 365-388. https://doi.org/10.1521/pedi.2008.22.4.365

Shorey, R. C., Anderson, S. E., \& Stuart, G. L. (2012). Gender Differences in Early Maladaptive Schemas in a Treatment-Seeking Sample of Alcohol-Dependent Adults. Substance Use \& Misuse, 47, 16-108. https://doi.org/10.3109/10826084.2011.629706

Tereno, S., Soares,I., Martins, E., Sampaio, D., \& Carlson, E. (2007). La théorie de l'attachement: Son importance dans un contexte pédiatrique. Devenir, 19, 151-188. https://doi.org/10.3917/dev.072.0151

Theakston, T. A., Stewart, S. H., Dawson, M. Y. et al. (2004). Big Five Personality Domains Predict Drinking Motives. Personality and Individual Differences, 37, 84-971. https://doi.org/10.1016/j.paid.2003.11.007

Toubiana, E. P. (2011). Addictologie Clinique. Presses Universitaires de France.

Young, J. E., \& Lindemann, M. D. (1992). An Integrative Schema-Focused Model for Personality Disorders. Journal of Cognitive Psychotherapy, 6, 11-23. https://doi.org/10.1891/0889-8391.6.1.11 